\title{
Article
}

\section{Inside the mediation room - efficiency, voice and equity in workplace mediation}

Saundry, Richard Arthur, Bennett, Anthony and Wibberley, Gemma Available at http://clok.uclan.ac.uk/14678/

Saundry, Richard Arthur, Bennett, Anthony and Wibberley, Gemma ORCID: 0000-0002-7827-8227 (2018) Inside the mediation room - efficiency, voice and equity in workplace mediation. The International Journal of Human Resource Management,, 29 (6). pp. 1157-1177. ISSN 0958-5192

It is advisable to refer to the publisher's version if you intend to cite from the work. http://dx.doi.org/10.1080/09585192.2016.1180314

For more information about UCLan's research in this area go to http://www.uclan.ac.uk/researchgroups/ and search for <name of research Group>.

For information about Research generally at UCLan please go to http://www.uclan.ac.uk/research/

All outputs in CLoK are protected by Intellectual Property Rights law, including Copyright law. Copyright, IPR and Moral Rights for the works on this site are retained by the individual authors and/or other copyright owners. Terms and conditions for use of this material are defined in the policies page.

\section{CLoK}

Central Lancashire online Knowledge www.clok.uclan.ac.uk

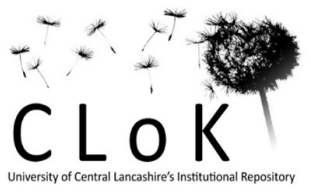


Title: Inside the Mediation Room - Efficiency, Voice and Equity in Workplace Mediation

Authors: Richard Saundry, Tony Bennett and Gemma Wibberley

Affiliations: Richard Saundry (when research was conducted iROWE [Institute for Research into Organisations, Work and Employment]; University of Central Lancashire, Preston, UK) Now (Plymouth Graduate School of Management, University of Plymouth, Plymouth, UK), Tony Bennett and Gemma Wibberley (iROWE [Institute for Research into Organisations, Work and Employment]; University of Central Lancashire, Preston, UK)

Correspondence details: Richard Saundry, Professor of HRM and Employment Relations, Plymouth Graduate School of Management, Mast House, University of Plymouth, PL48AA (richard.saundry@plymouth.ac.uk)

Acknowledgements: The authors would like to gratefully acknowledge the funding from Acas to complete the research and the generous contributions of all those who participated in the research.

Disclosure Statement: We have no conflict of interest to declare. 


\title{
Title: Inside the Mediation Room - Efficiency, Voice and Equity in Workplace
} Mediation

\begin{abstract}
Existing research into workplace mediation in the UK has tended to focus on managerial perceptions. Consequently, there has been a unitarist emphasis on the business case for mediation, revolving around its alleged superior efficiency properties compared to conventional rights-based procedures. This paper develops the research agenda in two respects: first, it foregrounds the experiences of participants in mediation through 25 interviews with individuals drawn from a variety of contexts. Second, it uses Budd and Colvin's (2008) triadic framework to extend the analysis beyond the efficiency of mediation to consider issues of voice and equity. In doing so it explores the role played by mediation within the negotiation and re-negotiation of workplace relations and also the way in which it shapes, and is shaped by, power and control. In the cases examined in the paper, mediation not only facilitated employee voice, but allowed subordinates to challenge the authority of supervisors and line managers. However, the influence of mediation on the balance of workplace power relations outside the mediation room was much more limited.
\end{abstract}

Keywords: workplace conflict, alternative dispute resolution ADR, conflict management, mediation, employee voice 


\section{Inside the Mediation Room - Efficiency, Voice and Equity in Workplace Mediation}

The profile of mediation as an alternative method for resolving individual workplace disputes has increased in recent years, as dissatisfaction with traditional rights-based disputes procedures and the cost of litigation over employment issues has grown (An author and Author A, 2014; Lipsky, Avgar, Lamare, and Gupta, 2012). In the UK, this has revolved around a 'business case' based on the perceived efficiency advantages of mediation over conventional disciplinary and grievance processes (Latreille, 2011).

This emphasis on the business case is partly rooted in the dominant methodologies within mediation research, which have rested on the perspectives and experiences of mediation coordinators, mediators, managers and trade union representatives. In contrast, academic research in the UK has largely ignored the 'voice' and experiences of employees, in supervisory or subordinate positions, who participate in mediation. This reliance on managerial and organisational perceptions has arguably led to a relatively narrow agenda centred on the efficiency benefits of mediation in terms of cost, speed and success. This reflects a fundamentally unitarist perspective of conflict and dispute resolution.

Budd and Colvin's (2008) triadic framework for assessing dispute resolution processes provides a way of extending the evaluation of workplace mediation beyond efficiency to include notions of employee voice and equity. For Budd and Colvin, efficiency largely relates to the speed and cost of the process, so in terms of the evidence to date, mediation may be seen as 'high efficiency' however, it arguably surrenders managerial authority over decision making. Voice reflects access to, and participation within, the mediation process while equity refers to the extent to which the outcomes of the process are seen as fair and just. Furthermore, in 
accepting that conflict is a function of the contest between the objectives of efficiency, equity and voice, Budd and Colvin's approach points to the importance of power relations in understanding and explaining mediation and other dispute resolution processes.

This paper develops the research agenda in two respects: first, it focuses on the experiences of participants in mediation through 25 interviews with individuals drawn from a variety of contexts. Second, it uses Budd and Colvin's (2008) framework to explore how notions of efficiency, equity and voice are played out in workplace mediation and assess the implications for the balance of power within the employment relationship. In particular, it poses two key questions: to what extent does mediation represent an opportunity for employees to challenge poor treatment? Can mediation provide a conduit for the reassertion of managerial prerogative?

The article is structured as follows. Firstly, a brief overview of the mediation literature is provided. Secondly, the methods for accessing disputants and analysing their stories are set out. Thirdly, the key findings are presented using Budd and Colvin's (2008) framework. The implications of these findings are then discussed with reference to the two research questions set out above.

\section{Literature Review}

Until relatively recently, the resolution of individual employment disputes in UK workplaces was largely confined to the application of disciplinary and grievance procedures, supplemented by specialist processes, in some workplaces, to handle matters such as absence, capability and bullying and harassment. While such procedures are generally underpinned by key principles of natural justice, outcomes are determined unilaterally by the employer with little or no access 
to third-party adjudication, unlike in the USA where some form of arbitration or mediation is a relatively common feature of grievance procedures (Colvin 2012, 2014). For most UK workers, the only way to access impartial adjudication over an individual employment dispute was, and is, to seek legal redress through an application to an employment tribunal.

Consequently it has been argued that disciplinary and grievance processes were developed in the UK to largely reinforce managerial control (Purcell and Earl, 1977; Thomson and Murray, 1976). Indeed, the rapid spread of such procedures in the UK during the 1980s and 1990s progressively removed individual disputes from the ambit of collective workplace regulation and so represented the re-assertion of employer prerogative (Colling, 2004; Edwards, 2000). Moreover, the spread of associated processes for the management of performance and absence have been seen by some as evidence of a Foucauldian 'panopticon' whereby the actions of workers are individualised and subject to managerial 'gaze' (Townley, 1993, p.234).

Workplace mediation arguably represents a break with this dynamic. Mediation can be defined as 'where an impartial third party, the mediator, helps two or more people in dispute to attempt to reach an agreement' (Acas/CIPD, 2013, p. 8). This tends to refer to situations in which specialised trained mediators are commissioned either from an external provider or an in-house mediation scheme. It has a number of key features; first, it is a voluntary process, in that the consent of both or all parties is needed and participants cannot be compelled to attend. Second, the process is confidential and whether the outcome or details of the mediation are revealed to managers and colleagues is a matter for the parties. Third, unlike conventional processes, decision making authority is removed from the 'manager' instead responsibility for any resolution is placed on the parties themselves with the mediator playing an impartial role in 
helping the parties to examine the issues underlying the dispute (Teague, Roche and Hann, 2011).

The use of workplace mediation and ADR has increased in recent years, albeit at different speeds, in Europe (EUROFOUND, 2010; Grima and Paille, 2011; Clark, Contrepois, and Jeffreys, 2012) and other countries including Australia (Forsyth, 2012), New Zealand (Corby, 1999), Japan (Benson, 2012) and most notably in the US where it is perhaps most firmly established (Lipsky et al., 2012; Stipanowich and Lamare, 2013). There is certainly evidence that interest in, and use of workplace mediation in the UK is growing. For example, requests for mediation on individual issues made to the UKs Advisory, Conciliation and Arbitration Service (Acas) doubled between 2004/5 and 2010/11 (Acas, 2005, 2011). However, it is not clear whether the rhetorical volume surrounding mediation in the UK has been fully matched by adoption. The latest Workplace Employment Relations Study (WERS2011) revealed that $17 \%$ of British workplaces, which experienced employee grievances, had utilised mediation (Others and Author A, 2014). Similarly, the nature of mediation seems to predicate its utilisation by medium and large, rather than smaller companies (Latreille, Buscha and Conte, 2012). Teague et al. (2011) also note that in Ireland there has been limited uptake of ADR in general, compared to the US, suggesting that this may be linked to different regimes of employment regulation.

The case for mediation is largely made from a unitarist perspective which emphasises its contribution to organisational efficiency. Its advocates argue that it provides an opportunity for early intervention before a dispute escalates. In this way it aims to resolve disputes that otherwise might lead to the use of extensive and convoluted grievance and disciplinary procedures, long-term absence of those involved, and in some cases litigation (Corby, 1999; 
Seargeant, 2005; Kressel, 2006). It is also suggested that mediation offers employers significant financial savings compared with more conventional rights based disputes procedures (Goldberg, 2005). Certainly, reported rates of resolution and participant satisfaction are high (An Author and Author A, 2014).

However, as outlined in the introduction to this article, Budd and Colvin argue that, in addition to efficiency considerations, examining equity and voice provides a pluralist analysis of dispute resolution mechanisms, which reflects the existence of competing interests within the employment relationship (Budd and Colvin, 2014). For Budd and Colvin, equity reflects the extent to which the outcomes of mediation are underpinned by fairness and justice. In certain respects mediation would appear to extend equity - decision-making is left in the hands of the participants and the process is facilitated by an impartial third party. Moreover, access to mediation should, in principle, be independent of status of organisational resource. Finally, in most cases, participants who are unhappy with the outcome of mediation can subsequently bring complaints through formal grievance procedures. One difficulty is that the lack of an impartial adjudicator means that outcomes are unlikely to be consistent across an organisation although 'since the parties retain control of the resolution in mediation, any inconsistencies are agreed to by the parties' (Budd and Colvin, 2008:9)

The open and negotiated nature of mediation processes would also seem to enhance employee voice. As noted above, a key feature of workplace mediation is that responsibility for decisionmaking is placed on the parties themselves. In this way mediation can be argued to represent an important extension of 'voice' and critically not one that is articulated or initiated by management. Some writers have emphasised the role of mediation in enabling workers to 'voice' concerns instead of being forced to 'exit' the organisation (Barsky and Wood, 2005; 
Berggren, 2006). Furthermore, the mediation room provides a safer and less intimidating environment in which to challenge managerial behaviours (Karambayya, Brett, and Lyle, 1992; Corby, 1999; Mareschal, 2002) in a way that is not open to them through conventional adjudicative disputes procedures under which management retain ultimate control (Wiseman and Poitras, 2002). Interestingly, recent case study evidence suggests that line managers may be particularly resistant to mediation, seeing it both as a threat to their authority and as a symbol of failure (Author A and Author C, 2012).

This in turn suggests that the interplay between efficiency, equity and voice points to a need to focus on the role played by mediation within the negotiation and re-negotiation of workplace relations and also the way in which it shapes, and is shaped by, power and control. As Latreille and Author A (2014) have pointed out, power relations are an important consideration both within and outside 'the mediation room'. In 2011/12, 70 per cent of charged-for mediations conducted by Acas involved a party who had authority over the other disputant (Acas, 2012). Consequently, inside the mediation room, the employee may be too intimidated to contribute fully to the process (Wiseman and Poitras, 2002). Furthermore, the power imbalance may not simply reside in the hierarchical relationship between the parties but also in the degree to which they are able to articulate their views providing a potential advantage to more senior, experienced and confident staff (Seargeant, 2005).

But, perhaps more importantly, power relations persist outside the mediation room, despite the best efforts of mediators to provide a semblance of equity during the mediation itself (Sherman, 2003). It could be argued that the emphasis in mediation is settlement and the restoration of the employment relationship in order to remove any impediments to the employers' productive requirements. Organizational imperatives to resolve issues quickly, in order to avoid cost, 
disruption and/or negative public relations, may not only pressure parties into agreeing to mediation but also implicitly coerce both mediator and disputants to settle (Coben, 2000). Perhaps more fundamentally, questions are raised about the effectiveness of individual dispute resolution processes that place the onus on subordinates to challenge management, especially in cases of alleged bullying, where power imbalances can be particularly problematic (Hoel and Beale, 2006). In such cases, it could be argued that the mediation process effectively internalizes workplace conflict, re-casting issues of unfair treatment through a unitarist lens into interpersonal clashes or communication breakdown. In short, responsibility for conflict is shifted from the manager to the managed. As such mediation could constitute a form of selfdiscipline (Edwards, 2000) whereby legitimate resistance is stifled and employer control is reinforced (Colling, 2004). Accordingly, it can be argued that mediation is ultimately a management process and a means of re-asserting control and quieting dissent.

Accordingly, it could be suggested that there is an inherent tension between the efficiency of mediation and the extent to which it delivers equitable outcomes. Moreover, the balance of these three dimensions will influence whether mediation challenges or re-asserts managerial prerogative and control. This issue is therefore examined in the subsequent section of this paper by analysing the experiences of 25 mediation participants using Budd and Colvin's framework to explore the extent to which mediation represents an opportunity for employees to challenge managerial authority or enables employers to re-assert their control over the employment relationship.

\section{Methods}


The sample for the research was constructed in two main phases. In the first, the researchers were provided with the contact details of individuals who had participated in workplace mediation conducted by Acas and who had agreed (in the feedback questionnaire completed after the mediation) to take part in further research. This yielded a total of 13 subjects from 18 original contacts. In order to supplement this, the researchers contacted other mediation services, and asked whether they would be prepared to assist in identifying additional subjects. Two private providers, two organisations with in-house schemes and Acas (North West) agreed, and this yielded a further 12 subjects.

Overall, therefore, the sample comprised of 25 subjects. An overview of the sample is provided in table 1 , below. The bulk of the cases examined were found in public sector organisations, only four respondents worked in the private sector, with a further two employed by what we could broadly define as not-for-profit organisations. All but one of the organisations was large or very large with their own HR departments or access to HR expertise. To this extent, although the sample could not be considered representative, its composition reflected the findings of earlier studies which have identified the far greater use of mediation within large public sector organisations (Author A and Author C, 2012; Author B, 2013) and that size of organisation impacts on the use of mediation (Latreille et al., 2012).

\section{INSERT TABLE 1 HERE}

Fifteen out the twenty-five cases were mediated by Acas, with six cases handled by in-house mediators and four by a private mediation provider. A small number of the organisations which had in-house mediators still chose to use external providers in specific cases, generally due to the seniority of the staff involved in the dispute. The majority of respondents were female. 
As the research team was dependent on self-referrals, there was no mechanism through which other disputants involved with specific cases could be contacted. However, the sample provides perspectives from both 'sides' of the employment relationship. Eighteen of the 25 cases involved disputes between a subordinate employee and their line manager, in which the dispute had featured a complaint from the employee about the actions or behaviour of their manager. In 9 of these cases, the employee was interviewed and in the other nine the manager was interviewed. The remaining 7 cases involved disputes between colleagues who had no direct hierarchical relationship. Therefore, the sample allows insights into how power relations shape and are played out within the mediation room and the extent to which mediation provides opportunities for employees to voice concerns and challenge managerial authority.

In-depth, semi-structured interviews were carried out with participants which lasted between thirty minutes and ninety minutes. Overall, 22 hours of interview data were collected. In total, ten interviews were conducted face-to-face and fifteen by telephone. It is important to stress that there was no evidence that this had any impact on the quality of the data gathered. It should also be noted that in the findings set out below, any identifying features have been removed to protect confidentiality. A topic guide (see Appendix 1) was co-developed by the authors based on their previous research into workplace mediation (An Author and Author B, 2011; Author A, and others, 2011; Author B, 2013; Author A and Author C, 2014) and used in all interviews ensuring consistency. The interviews attempted to examine: the evolution of the dispute; the initial attitudes of the interviewee to the idea of mediation; the interviewee's experience of the mediation process; the nature and sustainability of the mediation outcome; and the impact of participation in mediation on the attitudes and practice of the interviewee. 
The data was analysed by template analysis (King, 2004). The topic guide provided in Appendix 1 was used to identify a number of a priori key themes underpinning the research. These themes were then modified in response to initial analysis of interview transcripts and a 'template' developed which was then applied to the remaining dataset. Responses were then analysed using this template with existing themes refined and new themes added as issues emerged from exploration of the data. For instance, participants' concerns about the ramifications of not proceeding with mediation, highlighted the necessity to explore its 'voluntary' nature. The interviews were then re-examined to assess the weight of evidence in respect of these new themes. The whole team was involved in this template analysis to ensure consistency. Furthermore, participants were sent a draft of a report of the findings to assess the validity of its contents.

\section{Findings}

\section{Nature of the dispute}

Most of the cases within the sample involved an intricate blend of grievance and potential disciplinary issues. For example, the largest group of cases was made up of complex disputes that appeared to have their roots in attempts by a manager to raise or address perceived performance issues with a member of their team. Invariably, these problems had developed in a context of significant organisational change and an emphasis on more proactive management of performance. A fairly typical example was given by a manager in a large public sector organisation: 
...The background was huge losses against the agreed budget, lack of the right kind of direction, lack of success, lots of unmotivated people...but with that came a lot of people that have worked for the organisation...for, maybe at that point 20 years. (Case 1)

In such instances, staff were portrayed as resistant to change while managers were under pressure to improve efficiency and quality and apply more stringent policies in terms of performance, absence and capability. This was often perceived (whether rightly or wrongly) by the member of staff as unfair and in some instances as bullying. Accordingly, the demand for mediation was inevitably connected with organisational attempts to increase efficiency.

There were also four instances of alleged discrimination or bullying, which were seemingly unrelated to performance. In these cases, interviewees claimed that the alleged perpetrator had a history of such behaviour within the organisation but formal complaints procedures and processes were either not thought to be appropriate or had failed to produce a conclusive result.

Six of the 25 cases centred on differences in management style or conflict over operational strategy and typically involved a clash of personalities. The trajectory of such disputes appeared to revolve around the interpretation of the other party's behaviour. For example, one respondent explained a situation in which they 'tended to be very forthright' while their colleague 'tends to take things very personally'. For this respondent, what he considered to be normal behaviours were seen as being negative by the other party: 
I walk past in the corridor, or whatever, and I won't say anything because I've got my head in my bag or I'm on my phone but she doesn't see me on my phone...so 'he's ignoring me now'. (Case 23)

However, these cases also had significant implications for both employment relations and the effective functioning of the individuals and the teams in which they worked.

As can be seen from Table 1, in the majority of cases (14 out of 25) mediation was employed after the submission of a formal complaint or after the conclusion of an existing grievance or capability procedure. In a further 4 cases, no procedure had been enacted but the dispute had become protracted by the time mediation was considered. In all other cases, mediation was employed to avoid formal grievance or disciplinary procedures. Mediation was thus seen as a means of preventing the escalation of the dispute against the backdrop of the potential for the eventual dismissal or resignation of the staff involved and the threat of litigation.

\section{Efficiency}

The initial trigger for mediation mostly came from either senior managers or HR practitioners. In fewer cases, mediation was requested by the parties or stemmed from interventions from occupational health departments and (in three cases) trade unions and professional bodies. Therefore, it was largely a managerial intervention aimed at resolving very difficult situations in which procedures had failed and where there was a potential for significant cost exposure. The objective was essentially pragmatic - to get the parties working together again: 
...[The organisation] don't expect these two to be bosom buddies...they just need them to be able to conduct [themselves in] a professional manner that allows one to draw on the expertise of the other and vice versa. (Case 16)

There was rarely any expectation or desire for relationships to be transformed nor was mediation seen as a way of challenging behaviours (of either party). In fact, respondents, including a number of line managers, claimed that senior managers were not concerned about the outcomes or implications of the mediation as long as the dispute did not continue to have a negative impact on the organisation or incur further costs. In one case, the participants decided to inform the senior manager who had suggested mediation initially that the dispute had been resolved, but the e-mail was not even acknowledged. A manager who had faced accusations of bullying summed up the view of their organisation to mediation as follows:

'...they could chuck some money at it and resolve it and great and we asked for that, they ... we gave them a solution so they said, 'Yeah, pay for it just to get it sorted'. (Case 14)

Mediation was rarely suggested at the early stages of a dispute. Thus, in most cases, by the time mediation was used, the parties had developed extremely entrenched and 'frozen' views of the issues (Irvine 2014). In one instance, mediation had taken place nine months after a complaint was made:

I think perhaps we might have got to mediation sooner, in which case...perhaps feelings might not have become quite so entrenched...I think we hopefully might have had a better outcome. (Case 4) 
Another respondent explained that it was difficult to reach a resolution as mediation had occurred only after formal complaints of bullying had been made against her:

I think it would have been great to do, or to try and do mediation ahead of formal complaints of bullying...you've almost, set your ...stall out at that stage haven't you, from both sides...So he's said 'you're bullying me', I've said 'no I haven 't' and it's quite difficult to recover from that regardless of how successful the mediation is. (Case 15)

There was some indication that cases were more likely to be referred at an earlier stage where there was an in-house mediation scheme - this may be explained by greater managerial awareness or by the fact that contracting external mediators may have greater one-off cost implications.

Importantly, the evidence suggested that mediation was largely used as a pragmatic response which was simply aimed at finding a way for the parties to 'get back to work' rather than seeking more fundamental changes in attitude or behaviour. Restarting communication between parties who had stopped talking to each other or were unable to deal with each other in a professional or constructive manner was a crucial feature in a number of cases.

...if I was in the same position again, I would go for mediation but not necessarily because I think it's the be all and end all, but actually because it was a constructive process ...if you're working with people, you've got to try everything you can to make that relationship at least bearable. (Case 23) 
Therefore it was unsurprising that participants had little faith that mediation could be transformative. Although mediation offered efficiency in the short-term, arguably longer-term problems were not necessarily addressed. One interviewee, who had been the subject of bullying behaviour from a colleague, explained this as follows:

I think that a bully rarely identifies that they are a bully. So, they want to get through the process as quickly as possible. They tick the boxes and continue life as normal. Which is what he did. (Case 11)

In this case, a desire to resolve the case quickly and efficiently was counter-productive leaving underlying conflicts and potentially organisational problems of mistreatment unresolved.

However, from the perspective of line managers asked to take part in mediation, the use of mediation could act as a brake on efficiency. Where mediation had been enacted in response to attempts to manage performance, managers felt frustrated that the discussion focussed on the complaint about their behaviour rather underlying performance issues. For example, one manager felt uncomfortable talking about the return to work of a member of staff during mediation; when they felt that this was not going to be possible due to outstanding concerns over the individual's capability. In such cases there was a pervasive view that while mediation had resolved the initial complaint and in that sense led to resolution - it was a sticking plaster on a fundamental problem.

\section{Voice}


Most interviewees were reasonably positive about entering mediation and were also happy with the role of the mediator. They were felt to be impartial and to have allowed both parties to explain their positions. Even where the situation between the participants was very difficult, parties welcomed the opportunity for resolution and the chance to discuss their concerns with a third party outside the immediate organisational environment. An employee who had had main a complaint against their line manager explained this as follows:

"I felt that mediation might just be what we both needed...to talk openly about what was going on and maybe come out feeling much better and be able to take things forward. So after thinking about it I thought well I'd welcome that. I think I'd welcome anything other than you know the grievance and the long processes..." (Case 24)

For those who had made complaints against colleagues or managers, mediation offered a relatively safe environment in which they could have 'their say', which they felt would otherwise have been suppressed within conventional grievance or disciplinary procedures. Thus there was a sense in which power asymmetries within the workplace were attenuated within the mediation room and this in turn provided an environment in which 'voice' was facilitated.

Despite the mixed evidence of clear and sustainable resolutions, the vast majority of interviewees felt that their participation in mediation had been beneficial. Even where there was no settlement, taking part in mediation had provided disputants with a voice. Even for those participants who claimed to be victims of bullying and discrimination, access to mediation could be empowering: 
I think it's helpful because it gets your mind-set in the right place...because she had been bullying me and making me feel very uncomfortable at work, I had to turn the situation round...I've tried my best to make this situation better, I've done all I can, it's up to her now and if she can't um see that then it's her problem and I can't own her problem. I feel more empowered...I know that I can move forward. (Case 22)

Another participant, although sceptical about whether mediation would affect the behaviour of the other party (his manager, who he claimed had discriminated against him), argued that being able to voice his concerns on equal terms enabled him to deal with any future issues without the debilitating impact of formal procedures.

'Well I was sceptical about going forward, but I thought there was, what do they call it in the Middle East? A roadmap...however well we were going to get on...we won't jump to, I won't jump to a grievance...we can have these conversations without a mediator, so I can say to him...you're doing it again.' (Case 12)

Voice was not necessarily restricted to those who had raised complaints against their managers - in a minority of cases, managers welcomed the opportunity to have their say and try and explain their actions. In the following example, a senior public sector manager felt that he had been unfairly criticised for his decisions and mediation provided the space to discuss the context of his actions: 
'... I was able to just put it in the wider context of how I was... I've been seen as the kind of like the axe man... and I was able to explain... as a manager there's things you have to do that are unpleasant, it's how you go about and deal with them... I felt I was able to explain the wider context of how I operated, how that person perceived me and how I wasn't out to get [them]'. (Case 1)

However, more generally, managers against whom complaints had been made were reluctant participants casting doubt on the voluntary nature of workplace mediation. This is not to say that they were forced into mediation but that they felt that their co-operation was expected by their superiors and HR, or that refusal would reflect poorly on them if the matter escalated to a formal grievance or an employment tribunal. The following response was typical:

...it was put to me very nicely, and it, it wasn't insisted upon. I think it was just from my own point of view, in that it would go on file that I wasn't willing to undergo mediation. Although that was understandable, I just felt that it would work against me somehow. So, I sort of felt pressured. (Case 20)

Furthermore, the evidence cast doubt on the extent to which the opportunities for 'voice' offered by mediation were widely available. Interviewees stated that mediation was typically included within their grievance (and other dispute) procedures, therefore in principle there was access for all. However, in practice, mediation was more likely to be utilised when the staff involved were of a level of seniority that meant that: the dispute had an impact on key operational and strategic decisions; had a detrimental effect on others working in their teams; or carried a risk of high profile litigation. 


\section{Equity}

In this section, we examine the extent to which the outcomes of mediation were seen as fair and equitable. While, perceptions of the process of mediation and particularly the extent to which it allowed employees to 'voice' concerns to their line manager were generally positive, the outcomes of mediation did not appear to deliver a sense of fairness and equity. Fundamentally, participants, particularly those who had previously raised a concern relating to the behaviour of a colleague or manager, initially hoped that mediation would provide an opportunity for justice, and to correct what they felt were wrongs that they had suffered at the hands of the other party. One respondent explained that mediation was not what he was expecting:

Because what hurt me most was the fact that...such a fundamentally serious criticism had been made dishonestly, not a single shred of evidence...And it was the fact that someone can do so much harm and get off scot free which was the ultimate injustice to me, and what made me seriously upset. (Case 25)

However, this could cause problems when such illusions were dispelled on meeting the mediator. For example, the interviewee cited above, quickly felt that the mediator was simply aiming to 'call an end to hostilities.'

Most of the respondents who had brought complaints against a line manager were sceptical as to whether their manager's behaviour had fundamentally changed. For one respondent mediation was 'a waste of time' because 'it didn't do anything to him [the manager] did it?' This respondent argued that his manager was simply 'jumping through the hoops that he felt 
he had to jump through because HR told him he had to do this' (Case 19). Indeed, some were concerned that managers saw mediation either as a soft option, or something they had to do, and had no intention of adhering to any consequential agreements.

Perhaps not surprisingly, attribution of responsibility was a major issue for interviewees in cases such as this - in which those subject to discrimination or bullying (or allegations of) were concerned that agreement to take part could infer some degree of blame. This reflects a broad concern over the use of mediation in such situations. Namely that it can be used to abrogate managerial responsibility for unfair treatment and effectively internalise conflict, reinterpreting discrimination or bullying as a personality clash.

A number of respondents also felt that while mediation had its advantages, they were more used to, and therefore comfortable with the certainty of formal procedure. In addition, whereas within formal grievance processes, the details of the allegations would be provided to the parties, this was not necessarily the case within mediation. A senior manager working in the public sector explained that this had caused significant uncertainty and stress as mediation had made it difficult for individuals to defend themselves against allegations that they considered unfair:

'...allegations were made, but I was never provided with any information...I did eventually get the letter that [name] had written, just prior to mediation, but, you can imagine, we had quite a few months in between that...I never actually had all the information of what the accusations were about, and I think that's wrong. '(Case 10) 
A number of managers against whom complaints had been made questioned whether participating in mediation was in effect conceding that they had mishandled the situation in some way. Moreover, most of the line managers within our sample had little expectation that mediation would deal with what they saw as the underlying problem - the performance of the other disputant. This was partly related to the stage at which mediation occurred but also reflected the suitability of the process for examining managerial evaluations of capability:

“...my concern was could mediation resolve this, when actually the issue was a performance issue? Okay, that wasn't what she was raising, she was raising that I was bullying her ...but I couldn't see how we could separate the two..."

(Case 10)

Interestingly, in this case, the fears of the manager quoted above were in part realised and while an initial settlement was reached, this was not sustained.

\section{Discussion}

The academic debate over the use of mediation has tended to focus on its advantages over conventional rights based disciplinary and grievance procedures in terms of cost, time and high rates of success (An Author and Author A, 2014). In part, this reflects that fact that the bulk of the research has explored the perspectives of managers and mediators. In contrast, in this paper we have sought to explore the implications of mediation for workplace relations through the experiences of the disputants themselves. More importantly, by using Budd and Colvin's (2008) framework to consider issues of equity and voice, we have been able to examine two 
contrasting questions: to what extent does mediation represent an opportunity for employees to challenge poor treatment? Can mediation provide a conduit for the reassertion of managerial prerogative?

The findings outlined above suggest that the use of mediation, like conventional disciplinary and grievance procedures, is driven by the desire of the employer to limit the damage of disputes and avoid litigation by resolving disputes as quickly and as quietly as possible. In our sample, mediation was commissioned by senior managers or HR practitioners and primarily driven by efficiency considerations. It was primarily focussed on accommodation and on restoring employment relationships to facilitate production rather than providing justice or equity.

However, in our sample, mediation did facilitate the exercise of 'voice'. More specifically, in a significant number of cases, it provided a forum in which workers were able to contest their treatment at the hands of their managers and consequently challenge their authority. An important element of this was the opportunity for employees to enter into mediation on apparently equal terms with those who, outside the mediation room, would wield greater power. It has been argued that asymmetrical power relations between two participants will inevitably seep into the mediation process and may restrict the weaker party (Wiseman and Poitras, 2002); however, we found no clear evidence of this. Instead, it was the managers in our sample who found the mediation process more difficult. In most cases, managers were reluctant participants who felt pressured to take part by their own senior colleagues, contradicting the mantra that mediation is a voluntary process. 
Although mediation appeared to provide subordinate employees with new opportunities to challenge poor treatment, there was less evidence that the outcomes it generated were necessarily 'equitable'. Participants were generally positive about the mediation process and accepted that, in many cases, this had allowed them to 'move forward' or 'get back to work'. Furthermore, workers who had looked to mediation as a way of confronting managerial mistreatment felt better for having challenged the other party. However, participants, irrespective of their place in the organisational hierarchy did not see mediation as a vehicle of justice. Subordinates in disputes, who had commonly complained that they had been bullied or treated unfairly, tended to have little faith that the process would substantially change the behaviour of their manager in the long-term or hold them to account. In some respects, this reflects the concern, expressed in the literature that mediation can be used to avoid organisational action to deal with managerial mistreatment - instead bullying behaviours are recast as interpersonal disputes (Dolder 2004; Keashly and Nowell, 2011; An author and Author A, 2014). At the same time, managers who had been accused of unfair treatment or bullying felt that mediation did not allow them to defend themselves against what they often felt were unwarranted accusations.

The discussion above suggests that mediation can be used to confront poor treatment mediation provides a degree of 'voice' that conventional processes do not. Moreover, it does challenge the prerogative of managers who take part in mediation and in some cases may shape their subsequent behaviour. However, it is too simplistic to read the discomfort of line managers as evidence that mediation has the potential to overturn existing organisational power relations. This would make the common mistake of treating power and authority as interchangeable. Instead if power is seen as multi-dimensional (see for example Lukes, 2005), it could be argued that mediation does not disturb, and even reinforces, existing power 
asymmetries. We found little evidence that challenges to managerial actions that took place within the mediation process had any broader organisational outcomes. Although the prerogative of line managers was challenged, this was limited to the space in which mediation took place, with wider implications for the organisations insulated by confidentiality. In this way the properties of mediation that underpinned employee voice also undermined its potency to have wider organisational influence. Tellingly, within our sample, senior managers had little interest in the outcomes of the mediation as long as productive relations were restored. Therefore, mediation seemed to have little impact on broader power relations and the control exerted by the employer over the labour process.

\section{Conclusion}

Workplace mediation is attracting increased attention from practitioners, policy-makers and academics as an alternative to conventional rights-based disciplinary and grievance procedures. Extant research has pointed to the benefits of mediation in terms of cost and efficiency (Latreille, 2011) and the 'upstream' impact on managerial conflict resolution skills (An Author and Author A, 2014). Furthermore, it has been argued that in certain contexts mediation can have a transformational impact on workplace relations (BIS, 2011) and can provide a context in which managerial authority can be challenged (Author A and Author C, 2014). However, critics have suggested that mediation is simply a way of reasserting organisational control over the labour process and masking serious issues of mistreatment at work (Wiseman and Poitras, 2002; Keashly and Nowell, 2011).

The evidence presented in this paper suggests that mediation can provide an opportunity for employees to contest the behaviours and, in some circumstances, the authority of their 
managers. Critically, mediation is conducted by an impartial third party (as opposed to a manager) and the outcome is owned by the participants and not decided by the employer. These properties enhance access to mediation, facilitate employee voice and attenuate asymmetries of power inside the mediation room.

However, while mediation may have the potential to recast the relationship between participants, we found less evidence, within our sample, to suggest that its use can transform power relationships more widely within organisations. Critically, control over commissioning mediation generally lay with senior managers whose main goal was simply to clear difficult issues and shift the locus of responsibility for any conflict to the participants. Although the mediation room was relatively free from structures of authority, any challenge to management was constrained and captured within the mediation process through the commitment to confidentiality. Therefore while the authority of the manager taking part in the mediation may have been contested, there was no fundamental challenge to organisational order.

The size of the sample used in this research means that we must be cautious in considering its implications. Nonetheless, the findings outlined in this paper provide important insights for the continuing debate over the efficacy of workplace mediation. In many respects, they support previous research that points to the significant benefits of mediation for both employers and employees. In general, dispute resolution processes that are faster, safer and more likely to restore rather than destroy employment relationships can only be a positive step for organisations and workers. However, our findings suggest that while the management of mediation, and access to it, is controlled by the employer, it is unlikely to fundamentally reshape the balance of power that underpins workplace relations. 


\section{References [self references removed]}

Acas (2005). Annual Report and Accounts, 2004-2005. London: Acas.

Acas (2011). Annual Report and Accounts, 2010-2011. London: Acas.

Acas (2012). Acas Mediations 2011/12. Responses from participants and commissioners. Acas Research Paper, 16/12.

Acas/CIPD (2013). Mediation: an approach to resolving workplace issues. London: Acas.

Barsky, A. and Wood L. (2005). Conflict avoidance in a university context. Higher Education Research and Development, 24(3), 249-264.

Benson, J. (2012). Alternative dispute resolution in Japan: the rise of individualism. The International Journal of Human Resource Management, 23(3), 511-527

Berggren, K. (2006). Do formal mediation programs work in the settlement of employeeemployer disputes? Schmidt Labor Research Center Seminar Research Series.

BIS (Department of Business, Innovation and Skills) (2011). Resolving Workplace Disputes: A Consultation, London: BIS.

Budd, J and Colvin, A. (2008). Improved Metrics for Workplace Dispute Resolution Procedures: Efficiency, Equity, and Voice. Industrial Relations, 47(3), 460-479. 
Budd, J and Colvin, A. (2014). The Goals and Assumptions of Conflict Management in Organizations. In W. Roche, P. Teague, and A. Colvin (Eds.), The Oxford Handbook on Conflict Management (pp.12-29). Oxford: Oxford University Press.

Clark, N., Contrepois, S. and Jeffreys, S. (2012). Collective and individual alternative dispute resolution in France and Britain. The International Journal of Human Resource Management, 23(3), 550-566.

Coben, J. (2000). Gollum, meet Smeagol: a schizophrenic rumination on mediator values beyond self-determination and neutrality. Cardozo Journal of Conflict Resolution, 5, 65-86.

Colling, T. (2004). No Claim, No Pain? The Privatization of Dispute Resolution in Britain. Economic and Industrial Democracy, 25(4), 555-579.

Colvin, A. (2012). American workplace dispute resolution in the individual rights era. The International Journal of Human Resource Management, 23(3), 459-475.

Colvin, A. (2014). 'Grievance Procedures in Non-Union Firms' In W. Roche, P. Teague, and A. Colvin (Eds.), The Oxford Handbook on Conflict Management (pp.168-189). Oxford: Oxford University Press

Corby, S. (1999). Resolving employment rights disputes through mediation: the New Zealand experience. London: Institute of Employment Rights. 
Dolder, C. (2004). The contribution of mediation to workplace justice. Industrial Law Journal, 33(4), 320-342.

Edwards, P. (2000). Discipline: towards trust and self-discipline? In S. Bach and K. Sisson (Eds.), Personnel Management: A Comprehensive Guide to Theory and Practice in Britain, 3rd edition, (pp 317-339), Oxford: Blackwell.

EUROFOUND (2010). Individual disputes at the workplace: Alternative disputes resolution. Dublin: European Foundation for the Improvement of Living and Working Conditions.

Forsyth, A. (2012). Workplace conflict resolution in Australia: the dominance of the public dispute resolution framework and the limited role of ADR. The International Journal of Human Resource Management, 23(3), 476-494.

Goldberg, S. (2005). 'How interest based grievance mediation performs in the long term. Dispute Resolution Journal, 60(4), 8-15.

Grima, F. and Paille, P. (2011). Mediation in professional relationships in France: tactics and outcomes. Industrial Relations Journal, 42(5), 428-452.

Hoel, H. and Beale, D. (2006). Workplace Bullying, Psychological Perspectives and Industrial Relations: Towards a Contextualized and Interdisciplinary Approach. British Journal of Industrial Relations, 44(2), 239-262 
Irvine, C. (2014). "Do You see what I'm Dealing with here?" Vicious circles in conflict. Journal of Mediation \& Applied Conflict Analysis, 1(1).

Karambayya, R., Brett, J. and Lyle A. (1992). The effects of formal authority and experience on third-party roles, outcome and perception of fairness. Academy of Management Journal, 35, 426-438.

Keashly, L. and Nowell, B. (2011). Conflict, Conflict Resolution and Bullying. In S. Einarsen, H. Hoel, D. Zapf, and C. Cooper (Eds.), Bullying and Harassment in the Workplace: Development in Theory, Research and Practice (pp. 423-446). Florida: CRC Press, Taylor and Francis Group.

King, N. (2004). Using Templates in the Thematic Analysis of Text. In G. Cassell and G. Symon (Eds.), Essential Guide to Qualitative Methods in Organizational Research (pp. 266-270). London: Sage.

Kressel, K. (2006). Mediation revisited. In M. Deutsch and P. Coleman (Eds.), The Handbook of Constructive Conflict Resolution: Theory and Practice (pp. 726-756). San Francisco: Jossey Bass.

Latreille, P. (2011). Workplace Mediation: A Thematic Review of the Acas/CIPD Evidence. Acas Research Paper, 13/11. 
Latreille, P., Buscha, F. and Conte, A. (2012). Are you experienced? SME use of and attitude towards workplace mediation. The International Journal of Human Resource Management, 23(3), 590-606.

Lipsky, D.B., Avgar, A.C., Lamare, J.R. and Gupta, A. (2012). The antecedents of workplace conflict management systems in U.S. corporations: evidence from a new survey of Fortune 1000 companies. Mimeo.

Lukes, S. (2005). Power: A Radical View. London: Palgrave.

Mareschal, P. (2002). Mastering the art of dispute resolution: best practices from the FMCS. International Journal of Public Administration, 25, 1351-1377.

Purcell, J. and Earl, M. (1977). Control systems and industrial relations. Industrial Relations Journal, 8, 41-54.

Seargeant, J. (2005). The Acas small firms' mediation pilot: research to explore parties' experiences and views on the value of mediation. London: ACAS.

Sherman, M. (2003). Mediation, hype and hyperbole: How much should we believe? Dispute Resolution Journal, 58(3), 43-51.

Stipanowich, T. and Lamare, J.R. (2013). Living with ADR: evolving perceptions and use of mediation, arbitration and conflict management in Fortune 1,000 corporations. Harvard Negotiation Law Review, 19(1), 1-67. 
Teague, P., Roche, B. and Hann, D. (2011). The diffusion of alternative dispute resolution practices in Ireland. Economic and Industrial Democracy, 33(4), 581-604.

Thomson, A. and Murray, V. (1976). Grievance Procedures. Farnborough: Saxon House.

Townley, B (1993). Performance Appraisal and the Emergence of Management. Journal of Management Studies, 30(2), 221-238.

Wiseman V. and Poitras, J. (2002). Mediation within a hierarchical structure: how can it be done successfully? Conflict Resolution Quarterly, 20(1), 51-65. 


\section{Appendix One - Topic Guide}

- Role in the organisation and length of service

- Probe as to nature of organisation if necessary

- Previous knowledge of mediation either generally or through the organisation

- Previous attitudes (if any) to mediation

- Background to dispute - reasons for dispute and relationships between parties

- Alternative attempts to resolve the dispute

- Probe whether informal processes were used and relationship between mediation and procedure

- Point at which mediation was requested)

- Reasons for entering into mediation

- Probe as to who made the suggestion or referral to mediation (HR,

Occupational Health, Manager, Union Representative

- Initial response of interviewee to suggestion of mediation

- If negative probe why

- Extent to which interviewee felt compelled to attend mediation

- Probe whether voluntary and whether there was any pressure form employer

- Support received from employer - information provided and moral support

- Initial expectations of mediation

- Nature of the process

- Views as to the process

- Probe what worked well in the process and what could have been improved,

- Probe for views as to role of mediator (neutrality)

- Probe extent to which process was difficult/stressful

- Nature of outcome - was there an agreement?

- Probe perceptions of fairness and influence on subsequent behaviour and attitude

- Probe for sustainability of settlement

- Confidentiality and organisational learning

- Probe whether interviewees agreed to colleagues being informed of outcome

- Probe interest of organisation in outcome and follow up

- Impact on attitudes and organisational

○ Probe impact on attitudes of participants and wider organisational effects 